\title{
Transport expenditure and affordability: The cost of being mobile
}

Christo Venter ${ }^{1}$

Measuring and understanding the transport expenditure patterns of households and individuals is critically important for formulating pro-poor transport policies, as well as for monitoring their effectiveness. This paper reviews evidence on transport expenditure and affordability in South Africa, focusing especially on low-income and mobility constrained persons. The results indicate that a person's location along the urban-rural continuum significantly affects both their transport expenditure levels and the perceived severity of their transport affordability problems. Public transport users in displaced urban settlements and isolated deep rural locations and medium-income car commuters in suburbs and urban townships face the highest transport expenditures and affordability problems. Disabled and elderly people were found to have similar expenditure patterns and perceptions as travellers at large. Spatially targeted interventions in both transport supply and land use policy are suggested to address transport affordability problems in South Africa.

Keywords: transport cost; affordability; disability; poverty; livelihoods; public transport

Author Posting. (c) 2011 Development Bank of Southern Africa', 2011.

This is the author's version of the work. It is posted here by permission of 'Copyright Holder' for personal use, not for redistribution.

The definitive version was published in Development Southern Africa, Volume 28 Issue 1, March 2011. doi:10.1080/0376835X.2011.545174 (http://dx.doi.org/10.1080/0376835X.2011.545174)

1 Associate Professor, Department of Civil Engineering, University of Pretoria. Correspondence: christo.venter@up.ac.za 


\section{Transport expenditure and affordability: The cost of being mobile}

\section{Introduction}

The cost of living is a central concern in poverty alleviation and development studies. The monetary cost of day-to-day travel is attracting particular attention, as high volatility in energy prices is pushing transport affordability issues to the forefront of policy and public debates. The last few years have also seen a steady growth in scholarly interest internationally in the links between travel expenditure, affordability and welfare. In developed countries this interest has largely focused on concerns about the high cost of driving for lower-income households, often in the context of combined housing and transport trade-offs (Sanchez et al., 2007). In developing countries the affordability of public transport has attracted more attention, as policy and aid debates have gradually shifted from a preoccupation with justifying transport investment from an economic efficiency perspective (how can the overall cost of logistics be reduced?) to emphasising the promotion of equity and pro-poor objectives (in what ways does transport provide benefits and disbenefits for the poor?) (TRL, 2003).

The affordability question is directly relevant to policy makers in the transport field, as government policy on public transport subsidisation and regulation crucially affects transport prices. Empirical studies on public transport affordability have generally concluded that 'affordable public transport can provide a significant boost to the poor's mobility' (Bryceson et al., 2003). However our understanding of the links between transport costs, affordability and wider demographic, land use and economic patterns is insufficient to support the development of robust policies to achieve this significant boost, or to monitor their effectiveness. For example, the South African Government uses the number of households spending more than $10 \%$ of their income on public transport as its most important indicator of transport affordability (DoT, 2006), ignoring the variation in aspirations and consumption trade-offs across households in different locations (Venter \& Behrens, 2005).

This paper addresses this deficiency by exploring the variation in transport expenditure patterns and their links to affordability perceptions among transport user groups resident in different geographic settings in South Africa. The focus is specifically on transport users who might be considered more vulnerable to travel expenditure shocks, including disabled, elderly and low-income persons. Disabled and elderly travellers typically face high affordability constraints due to a combination of lower incomes and restricted mobility options - hence the identification of affordable travel as among the pertinent needs of disabled persons by the 1997 Integrated National Disability Strategy (OSDP, 1997).

Methodologically, this analysis adopts a quantitative approach that complements more qualitative in-depth studies of household-level links between mobility and livelihoods (e.g. 
Mahapa \& Mashiri, 2001; Bryceson et al., 2003). The analysis is largely based on data from the 2003 National Household Travel Survey in South Africa, the largest to date, providing detailed data on household travel patterns.

The question of whether vulnerable persons can afford transport is clearly not an easy one to answer. It depends on the definition of affordability that is adopted. We take an inductive rather than a normative approach, in which we let the data reveal as much as possible about the question. The point of departure is that unaffordability of transport can be detected empirically in at least one of four ways:

- By examining the actual cost of travel, both in absolute terms and relative to a person's or a household's income;

- By examining actual travel behaviour, to detect instances where unaffordability of travel options leads to suboptimal mobility patterns such as suppression of travel;

- By evaluating people's subjective perception of the affordability problems they face; and

- By comparing each of the above across groups of people to identify instances of relative deprivation.

The paper employs all of these approaches, with the overall intention of developing a coherent picture of transport expenditure and affordability patterns across sections of the South African population. The paper starts with a review of previous evidence on transport expenditure and affordability, and related measurement issues. We then explore travel behaviour and affordability constraints among disabled and elderly people, with reference to suppressed travel and its reasons. Then follows a broader exploration of the spatial differences in travel expenditures and affordability across South Africa, and the relationship between geographic and user-related factors and affordability perceptions. The final section summarises the insights gained and suggests directions for further research.

\section{Transport expenditure, affordability and livelihoods}

\subsection{Transport expenditure in developing countries}

A review of studies in the urban transport and development fields shows that transport affordability is considered an issue of importance throughout the developing world. Empirical evidence suggests that, although transport costs as a share of household expenditure vary greatly across space and time, overall transport expenditure increases strongly with income, but tends to be regressive as transport costs consume a larger share of income among poorer households (for in-depth international reviews see Carruthers et al., 2005, and Diaz Olvera et al., 2008). 
The regressive nature of transport costs is illustrated for South Africa in Figures 1 and 2, which show the share of households' expenditure on transport (including all car, public transport and hired car expenses) and other major consumption items, expressed as a percentage of all expenditure and all income respectively. Among the lowest three income quintiles, transport comprises around $12 \%$ of all consumption, but this rises to $24 \%$ for the richest households. A large part of the difference is due to the higher use of the (more expensive) private automobile among higher income groups. However, as incomes rise much faster than total consumption, the share of income going towards transport is much higher among the poorest fifth of households (21\%) than among higher income households (12 to $16 \%)$. Total consumption for the lowest income quintile exceeds total income, reflecting the prominence of credit and non-monetary income sources.

\section{[INSERT FIGURES 1 AND 2 HERE]}

Both the higher significance of transport expenditure and the shortage of a savings cushion make the poor more vulnerable to shocks in transport costs. This has been evidenced in South Africa (Hendriks \& Lyne, 2003), Zambia and Cameroon (Diaz Olvera et al., 2008), Zimbabwe (Nyarirangwe \& Mbara, 2007) and Argentina (Carruthers et al., 2005), where data showed that poor households' travel expenditures were very elastic in response to structural adjustment policies or other economic shocks in the 1990s and 2000s.

In many cases poorer households pay more (in absolute terms) for public transport trips than their richer counterparts do. Reasons for this discrepancy include the poor location of many low-income households in the urban periphery (where low demand and long travel distances push up fares) (Gannon \& Liu, 1997), and a high dependence on informal transport modes with unsubsidised fares (Diaz Olvera et al., 2008). High transport expenditures are thus of concern because they can compromise a poor household's ability to access needed services and livelihood enhancing opportunities that can lead to an improvement in living conditions (World Bank, 2002). As evidence of this, various authors have cited the lower trip rates observed among low-income public transport users (Diaz Olvera et al., 2008), unreasonably low ratios of poor households' disposable income (after subtracting food and housing) to the typical public transport fare (Carruthers et al., 2005; Diaz Olvera et al., 2008), and the substitution of low-cost modes, such as walking, for higher-cost modes (Gomide et al., 2005). In South Africa, for instance, more than half of the poorest people walking long distances to work do so because of the unaffordability of other options (Venter \& Behrens, 2005). Furthermore, the impacts of unaffordable motorised transport have a gender dimension. Lowincome women more often use slower, cheaper modes, which lengthens their travel times and imposes an additional burden in terms of time poverty on them and their families (Turner \& Fouracre, 1995). 


\subsection{Travel costs and social exclusion in the developed world}

In the US and Europe, research on transport expenditure has evolved in the context of concerns about the broader social exclusion effects of the lack of affordable transport for households captive to the automobile. The Surface Transportation Policy Project (STPP) and the Center for Neighborhood Technology (CNT) have been tracking the rising cost of transport and its effects on US households for several years (STPP, 2003; Bernstein et al., 2005). More recently, transport and housing expenses have been analysed together, in a more explicit acknowledgment of the complex trade-off between residential location, travel distance and travel mode, and the way this affects transport costs (Lipman, 2006; Sanchez et al., 2007). The work indicated how peri-urban households incur the highest combined transport and housing costs in US cities - a fact that may put home ownership (and the wealth creation opportunities that may follow) out of reach for many low-income families (STPP, 2003). Obvious parallels exist in South Africa, where the combined cost of home ownership and car use in the suburbs might impose high cost burdens and social isolation on emerging middle-income households - an issue that has not received much scholarly attention.

\subsection{Transport expenditure of disabled and elderly travellers}

The link between disability and poverty in developing countries is well known: the two are mutually reinforcing and enduring (DFID, 2000). There has been no systematic study of the type and extent of the constraints the disabled and the elderly face when it comes to affording transport, but anecdotal evidence suggests that these constraints may be severe. For instance, focus groups with disabled people in Accra, Ghana, identified high transport expenses as one of the problems that prevented livelihood improvement (TRL, 2003). In a review of mobility and accessibility problems disabled people face in Africa, Mexico and India, Venter et al. (2002:7) found that 'cost issues appear to be one of the most important barriers to greater mobility, both in terms of accessing and maintaining mobility devices and in terms of affording to travel by public transport', as the disabled often have to pay extra for taking wheelchairs and companions on minibus-taxis.

Elderly people, whether they are disabled or not, tend to be similarly constrained. Studies in rural South Africa have shown that their transport problems are frequently related to affordability, as they tend to have incomes that are inadequate to cover transport to health centres, markets, pension payout points and social activities (Mashiri et al., 2008).

\subsection{Defining and benchmarking transport affordability}

While the measurement of individuals' or households' expenditure on transport is (at least conceptually) straightforward, linking this expenditure to a normative notion of affordability is more problematic. Transport affordability has been defined as 'the ability to undertake transport movements (make necessary journeys to work, school, health and other social 
services, and make visits to other family members or urgent other journeys) without significantly constraining the ability to undertake other activities of importance' (Carruthers et al., 2005:2), but the definition of 'necessary journeys' is both nebulous and depends in important ways on trade-offs with other consumption items such as housing.

The World Bank points out that the urban poor may choose less accessible housing locations because this best serves their overall interests (in terms of availability of shelter, access to activities, and so on) (Gannon \& Liu, 1997). Their high mobility needs, and the heavy burden of transport costs that results, is thus a symptom of their poverty rather than its cause. In such cases, high actual transport expenditures cannot automatically be interpreted as evidence of the unaffordability of transport.

It is for this reason that some analysts have turned to a synthetic index representing the average public transport fare for a standardised 10-km trip length and an assumed minimum desirable number of monthly trips, expressed relative to the average income of households in a city, to measure the affordability of public transport (Carruthers et al., 2005). Litman (2007) endorses the approach of linking affordability to accessibility (i.e. the range of opportunities that can be reached affordably) rather than actual mobility, to improve the evaluation of affordability benefits of transport policies.

There are, however, methodological problems when it comes to measuring expenditure, including problems of definitional inconsistencies (Carruthers et al., 2005) and dependencies on the type of measurement instrument used (Diaz Olvera et al., 2008).

In short, transport affordability cannot be assessed by looking at observed or actual expenditures only, as it is impossible to separate cause from effect. However, comparative assessments of expenditure data, especially when supplemented by other objective data (such as modes used and trip frequencies) and subjective data (such as perceptions of affordability), can provide useful insights into consumption behaviour and priority areas for action.

\section{Data}

The data for this analysis is from the National Household Travel Survey (NHTS) (DoT, 2005), conducted in 2003 by the South African Department of Transport using home interview surveys of 171519 individuals (45 556 households). Its purpose was to establish a baseline dataset of mobility levels, travel patterns and household perceptions of transport problems across South Africa. The survey provides the most complete database of transport use in the country to date and allows comparison across various geographic areas and settlement types.

One of the explicit objectives of the survey was 'to ascertain the cost of transport for individuals and households and to assess the extent to which they can afford to pay for the mobility which is essential for their survival' (DoT, 2005:5), but with the exception of some 
small-scale studies (e.g. Kane, 2006) little targeted analysis of affordability issues has been done.

Disability was defined using a functional definition related to travel, namely 'Is [respondent] limited in his/her daily travelling activities because of any disability lasting six months or more?' By focusing on travel functionality only, the survey failed to reflect the true incidence of disability in the surveyed population - in fact the $2.3 \%$ incidence of disability is less than half the figure of 7\% identified by the 1996 national Census (Venter et al., 2002). Furthermore, by allowing proxy reporting of disability, further biases may have been introduced.

For the purpose of this analysis elderly persons were identified as those over 65 years, as this is the common retirement age in South Africa. Persons who were both elderly and disabled were included in both groups.

As a working definition, public transport is taken here to include commuter rail, fixed-route bus services (both subsidised and unsubsidised) and unscheduled shared-ride minibus-taxi services.

\section{Analysis and results}

\subsection{Immobility and transport affordability among disabled and elderly persons}

People travel because they need to engage in activities. The absence of travel for any reason typically termed immobility - is therefore usually taken as a cause for concern and an indicator of the existence of latent or unsatisfied demand for activity participation. The analysis adopted a comparative approach by comparing immobility levels across groups defined by their disability/elderly status, settlement type and income level.

Immobile persons are defined as those who reported not making any trips out of the home on the randomly chosen survey day - including trips by all modes, even on foot. Figure 3 shows the percentage of immobile persons per income group, settlement type and person type. Settlement type (obtained by categorising households either as urban - including cities and towns - or rural) was used as a simple way of capturing geographic differences. Households were classified into three income categories, each containing roughly a third of households in urban and rural localities respectively, and taking the different income distributions across settlement types into account.

Approximately half of all the disabled and elderly did not travel outside of the home. This is broadly twice the figure for the population at large, which indicates relatively high levels of immobility among the former group. The disabled are in general slightly more immobile than the elderly (statistically significant $-\mathrm{p}<0.05$, $\mathrm{U}$ test). 
It is clear that settlement type has an important effect on mobility: urban people of all income groups are more mobile than rural people. The relationship of income to immobility differs for rural and urban people. In urban areas, rising incomes buy mobility for more people (all persons), but not for disabled persons, who have the same levels of immobility regardless of whether they live in low or high income households. This suggests that activity and travel opportunities for the disabled in cities are constrained by factors other than affordability. Among rural people in general, rising incomes are less strongly associated with rising mobility, which suggests that geographical factors such as long distances and constrained activity opportunities affect everybody's ability or desire to travel. Among disabled rural people, higher incomes are strongly and counterintuitively associated with higher levels of immobility, as compared to lower incomes. This could indicate that higher-income disabled persons in rural areas find themselves in isolated places where even walking access to activities is unavailable.

[INSERT FIGURE 3 HERE]

To further explore the underlying reasons for the observed differences in immobility, the reasons given by immobile respondents for their lack of travel were categorised as personal reasons not directly related to travel conditions, such as 'did not need to travel' and 'not well enough to travel'; affordability reasons such as 'public transport too expensive' or 'had no money'; access-related reasons such as 'no available public transport' or 'no suitable transport for disabled'; and other reasons, which were unspecified. Table 1 shows the results.

[INSERT TABLE 1 HERE]

It is clear that personal (non-travel-related) reasons are responsible for the bulk of immobility among all groups. Affordability reasons were directly identified as the main reason for not travelling in less than $10 \%$ of cases among all the groups, but more so for rural than for urban households. Transport affordability is perceived as more of a problem among low-income than high-income households, as can be expected. Significantly, affordability reasons were outweighed by access-related reasons in the case of disabled non-travellers, but not in the case of elderly non-travellers. This suggests that disabled persons who are willing and able to travel more frequently face their first constraint in the form of (in)accessibility of transport (both to vehicles and to networks), while affordability is less often perceived as the main problem. 


\subsection{Disabled and elderly persons' perceptions of transport affordability}

General perceptions of transport affordability as a problem were assessed by comparing responses to the question 'What are the two most important transport problems experienced by this household?' across the respondent groups (Table 2). 'Access problems' include problems of inadequate spatial or temporal availability of public transport, while 'service quality problems’ include all problems related to comfort, convenience or travel time.

[INSERT TABLE 2 HERE]

A similar pattern emerges as above. Affordability problems decrease with rising incomes. In urban areas affordability is seen as a problem by between a tenth and a fifth of households only; accessibility/availability and service quality problems are seen as more problematic. Significantly, urban disabled and elderly respondents' perception of their households' transport problems is very similar to that of the population as a whole.

In rural areas, however, perceptions are quite different. Affordability problems are mentioned by (proportionally) up to three times as many rural households as urban ones, across all income groups.

In summary, then, the data confirm that vulnerable groups see transport affordability as a significant problem, especially rural and low-income populations. However it appears that the actual impacts of unaffordability, in terms of constraining necessary travel, vary significantly according to a person's geographic environment. In urban areas transport unaffordability limits some travel for the poor generally, but not for disabled and elderly travellers specifically: for them, trip-making is constrained more by accessibility limitations than by cost concerns. In rural areas, trip-making is constrained for everybody, by limited opportunities at least as much as by affordability problems. It follows that, in both cases, improving the affordability of transport (for instance by subsidising fares) may benefit some users, but that other more binding constraints on mobility, such as limited transport availability and quality, need equal attention.

\subsection{Actual public transport expenditure and travel behaviour of disabled workers}

Turning from the immobile to the mobile, it is instructive to compare the actual travel costs across groups of frequent travellers. The hypothesis is that disabled travellers face higher travel expenditures than other travellers. Anecdotal evidence suggests that they might, for reasons indicated earlier. 
Frequent travellers are defined as those who regularly travel to work. Although costs for nonwork trips are no less relevant, the survey asked detailed questions only about work (and education) trips. We also focus only on public transport expenditures, firstly because travel costs were only reliably available for public transport trips (the expenditure data provided by car users are notoriously unreliable - Behrens \& Venter, 2006); and secondly because the hypothesis relates to public transport modes only.

[INSERT TABLE 3 HERE]

Table 3 summarises the data for disabled and all workers in urban and rural locales respectively. The sample sizes of disabled workers in both types of settlements are too small to support rigorous analysis - in itself perhaps an indication of the disadvantaged position of many employable disabled persons in society. What data we have indicate that in urban areas the hypothesis is rejected as disabled workers on average pay less per public transport trip than workers at large (R3.88 compared with R4.94). The same holds true for public transport cost at the monthly level (R164 compared with R202 per month). The difference in per-trip cost is statistically significant at a $10 \%$ significance level (t-test). However, as disabled persons earn less on average, their public transport expenditures consume a slightly larger share of personal income than is the case for all workers.

In rural areas the situation is reversed: average per-trip and monthly costs are higher for the disabled than for all workers. However, as none of the differences are statistically significant ( $p=0.05$, t-test), we cannot conclude that the disabled pay more for the same public transport trip than other users do.

\subsection{Public transport commute costs and geographic location}

The results so far suggest that a person's location along the urban/rural divide affects their transport expenditure at least as much as their personal characteristics do. It is worth examining the impact of location in more detail, as a better grasp of the links between geography and transport affordability could help in the formulation of effectively targeted poverty relief policies.

The geographic variation in public transport costs across South Africa is evident in Figure 4. The map plots the average public transport cost reported by workers using public transport, averaged by the home zone of the respondent. Zones with higher public transport costs seem to be concentrated around metropolitan areas, but also extend into deep rural areas. Clearly a more finely graded typology is needed than the crude urban/rural dichotomy used earlier, to help explain these cost patterns. We used the rural typology developed by the CSIR (Mhlongo et al., 1999), which classified rural and urban areas into broad classes to reflect 
similarities in land tenure, land use intensity and accessibility to major corridors and employment complexes. The typology was simplified to provide the following six classes for the present purpose, into which all 334 NHTS analysis zones were classified:

- Rural: arid agriculture - low-intensity farms and small towns, with sparse public transport services and most workers living close to their jobs.

- Rural: commercial agriculture - medium- to high-intensity farming areas and small towns with medium population densities, mixed economies and longer commute distances. Concentrated in the higher-rainfall southern and eastern portions of South Africa.

- Rural: homeland - former homeland areas with medium to high population densities, low-income populations and low functional connections with urban areas. Includes large parts of the Eastern Cape, Kwazulu-Natal and Limpopo Provinces.

- Urban: metro core - central business districts (CBDs) of metropolitan areas

- Urban: periphery - lower density suburbs around metro cores and medium size towns with an urban character and urban commute patterns.

- Urban: hinterland - displaced low-income residential settlements on urban fringes, but functionally connected with the urban economy. Typically poor transport connections and long commute distances. Includes areas such as Winterveld/Soshanguve near Tshwane and the Dimbaza/King Williams Town corridor near East London.

\section{[INSERT FIGURE 4 HERE]}

Table 4 shows the average public transport expenditures for each of these geographic classes. There are significant variations across the six types, confirming that public transport costs are systematically linked to the type of urban or rural area considered. Table 4 also shows data on affordability perceptions and average mode shares. Public transport trips are cheapest in arid rural zones, and seen as unaffordable by only $13 \%$ of residents. Walking is a viable option for many. Despite the thin demand for public transport, which would suggest that fares should increase to cover the low economies of scale, fares are kept low by users' low ability to pay.

Trip costs increase in commercial rural and especially in rural homeland locations. These areas are important as together they house about a third of workers nationally. Rural homeland residents identify affordability strongly as a problem, and seem to have fewer alternatives to taking public transport to get to work, such as walking. It is likely that this lack of modal competition, together with long travel distances, restricted opportunities for realising economies of scale benefits, and poor road conditions, contributes to raising fares in these areas. 
In urban zones public transport is generally more expensive than in rural areas and is used more extensively than either non-motorised modes or car modes. In general city dwellers' public transport costs rise as they are located further and further away from the CBD, in concert with rising travel distances. Thus the cost of mobility is highest in the displaced semiurban hinterlands, typically former homelands lacking substantial local employment accessible on foot, forcing many workers to make long, expensive public transport trips. The availability of heavily subsidised bus and rail services in some of these areas may help reduce fares but evidently does not substantially alter the picture.

\section{[INSERT TABLE 4 HERE]}

Overall, the costs of accessing work opportunities via public transport vary substantially across settlements, depending on a number of factors. We did not systematically examine these factors - more disaggregate price studies would be needed for that - but the aggregate evidence suggests a complex pattern. Many factors affecting transport costs are inherent to the location type, such as the pattern and density of land use development, the general cost of living and road infrastructure quality. Market economics - including the extent of competition and economies of scale - also play a role, although, as evidenced by the higher prices observed in urban areas with generally thicker markets, it is likely that public transport pricing (especially in the minibus-taxi industry) is driven at least as much by operators' desire to extract rent from higher income user populations as by cost considerations.

\subsection{Commute cost, personal characteristics and travel behaviour}

Having established the importance of the spatial environment to determining travel costs, we turn now to demographic and behavioural factors. The range of travel expenditures incurred is likely to be much larger when considering travel by all modes, instead of public transport only. The key question addressed in this section is, can groups of transport consumers be identified - with reference to their travel and personal characteristics (such as income) - with distinctly different expenditure/affordability conditions, when considering travel by all modes?

To estimate the required individual-level data the following procedure was followed:

1. Commute trip costs were estimated for all workers in the NHTS sample. For public transport and non-motorised travellers the trip costs are self-reported. For car users, self-reported trip cost data are not reliable (Behrens \& Venter, 2006), necessitating estimation of representative trip costs. Car ownership costs were determined from the annual expenses reported in the 2005/6 South African Income and Expenditure Survey (StatsSA, 2008), and adjusted according to the income level, commute frequency and 
urban/rural status of each car user. Variable costs per trip were estimated on a distance basis using fuel prices for 2003, reported travel times and average car speeds (taking typical congestion levels into account). Car passengers were assumed to contribute to the cost of their trip only when the respondent explicitly reported cost data (typically for informal lift clubs). The resultant car trip costs were, as a whole, higher than the (marginal) costs individual car users typically perceive, but more reflective of the full direct costs of car travel.

2. A heuristic clustering exercise was performed to find optimal clusters of individuals that are distinctly different in terms of either their average costs per trip, or the average percentage of income spent on transport, or the average affordability perception. Variables used to define clusters included the mode used, personal income and trip length. Where relevant, optimal cut-off values of income and trip length between clusters were determined using ANOVA tests such that between-group differences were maximised relative to the within-group differences in these variables (all differences were significant at the 0.01 level).

The result of this estimation and clustering exercise was the identification of nine distinct clusters or person types, which define commuter groups facing distinctly different expenditure/affordability realities. The clusters are as follows (see Table 5):

- Short walkers (17\% of commuters) - people commuting to work on foot and walking for less than 20 minutes (approximately one kilometre) one-way.

- Long walkers (13\% of commuters) - people commuting on foot for more than 20 minutes. Long walkers have slightly lower average incomes and perceive affordability problems more severely than short walkers, suggesting that some people walk long distances because they cannot afford motorised transport. Cross-tabulation with geographic location type (not shown in Table 5) revealed that about half of walkers (both short and long) live in the commercial rural settlement type.

- High-income public transport users (1\% of commuters) - a small fraction of public transport commuters who have personal incomes of over R6000 per month. These commuters tend to spend only 3\% on average of their personal income on transport. Most of them travel by taxi and live in urban suburbs and townships well-served by taxi operators.

- Medium-income public transport users (17\% of commuters) - people who have personal incomes of between R1500 and R6000 per month and spend on average 9\% of their income on public transport.

- Low-income public transport users (17\% of commuters) - people who have personal incomes of less than R1500 per month and spend on average 21\% of their incomes on transport. This group also perceives the most severe problems with transport affordability: 
almost a quarter of households identified unaffordability as among their top two transport problems.

- Extreme car users (2\% of commuters) - car users who drive more than 80 minutes oneway to work, and thus typically live far away from their jobs. On average this group spends more than R50 per trip to get to work; monthly notional commute costs exceed their personal incomes by 25\%. These estimated car travel costs are unrealistically high; in practice extreme commuters can be expected to reduce their costs by purchasing below-average priced cars and sharing costs with family members and paying passengers (neither of which would be reflected by this data). Extreme car users have, on average, only medium incomes of around R4400 per month.

- High-income car users (11\% of commuters) - people with incomes above R6000 per month, who spend on average $20 \%$ of their incomes on travel to work and have the lowest perceived affordability problems among all groups.

- Medium-income car drivers (15\% of commuters) - people with incomes below R6000 per month and spending as much as $80 \%$ of their income on travel. This group faces high expenditure burdens. Surprisingly, they do not seem to see affordability as a particularly severe problem. The estimated costs compared favourably with data calculated from the 2005/6 Income and Expenditure Survey, indicating that, on average, the poorest third of urban households who own cars spends two thirds of their income on car use. Once again, cost sharing from paying passengers and family members may help relieve the cost burden. Regardless of the exactness of the amount, the data indicate the very high cost burden of mobility borne by medium income households who choose or are forced (by a lack of suitable alternatives) to use motor vehicles.

- Medium-income car passengers (7\% of commuters) - because the direct costs borne by passengers are probably underestimated, this group is shown to spend only $3 \%$ of their income on travel.

[INSERT TABLE 5 HERE]

The large range of expenditure/income ratio data across the nine commuter groups shows that the mode used has a defining impact on the proportion of their income people spend on commuting. However the expenditure/income ratio on its own does not correlate very strongly with the severity of the affordability problems as perceived by the individual. Commuters' tolerance for high transport expenditures seems to differ according to their mode choice. The role of travel mode and other objective factors in determining affordability perceptions are examined in the following section. 


\subsection{Factors affecting transport affordability perceptions}

In order to examine the relationships between the numerous trip-specific, geographic and personal characteristics considered so far, and the users' perception of the affordability of transport, we use a multivariate analysis approach. An understanding of these relationships might produce further insight into which factors most strongly affect (subjective) affordability, while controlling for each of the other factors.

A disaggregate binomial probit model is estimated with the affordability indicator (taking the value 1 if affordability was identified as among a household's two most important transport problems) as the dependent variable. Independent variables include all the location type and commuter type categories identified above (introduced as dummy variables). Additional variables are included to test the hypotheses that, everything else being equal, people perceive longer distance trips as less affordable; people perceive trips made by the minibustaxi mode as less affordable; and having a disability leads to an increased unaffordability perception (see Table 6). Trip distances were captured through a dummy variable indicating whether or not the work trip destination was in the same zone as the worker's home. The model estimates the contribution of each of the independent variables to increasing the likelihood that an individual will perceive unaffordability as a transport problem.

\section{[INSERT TABLE 6 HERE]}

The results shown in Table 6 indicate that location type variables are the strongest predictors of affordability perceptions. People living in rural homeland areas are significantly more likely than others to report transport unaffordability as a problem, followed by those living in urban hinterland and rural commercial localities. This confirms the results in Table 4, which show that almost a third of commuters living in rural homeland areas identified affordability as among the top two transport problems they face. By implication, patterns of spatial development and transport supply in areas with rural homeland, ex-urban and commercial farming characters create conditions in which affordable transport is difficult to deliver (from the subjective point of view of the user), regardless of the mode that is considered or the personal characteristics of the potential user. In urban areas, in general, the further commuters are located from the metropolitan core the more severely they perceive their affordability problems, as indicated by the increasing coefficient values.

Apart from these spatially defined factors, mode use has a secondary correlation with affordability perception. Medium and low-income users of public transport and people who walk long distances to work report the most severe affordability perceptions. Among public transport users, use of the taxi mode does not in itself contribute to higher unaffordability (note the insignificant sign of the taxi variable), despite the fact that urban taxis tend to be more expensive on a per-kilometre basis than subsidised buses and rail. The reason for this is 
probably related to the fact that trip lengths tend to be shorter for the taxi mode, thus reducing the overall cost difference between the modes. There is no strong evidence that disabled commuters perceive more severe affordability problems than others with similar residential and income characteristics. Lastly, everything else being equal, spending a higher proportion of one's income on transport is associated with a perception of higher unaffordability, indicating that there might indeed be a role for this proportional indicator to measure affordability, but only within groups with similar modes, incomes and locational characteristics.

\section{Discussion and conclusions}

Rising energy prices are making transport expenditure and affordability a problem of increasing seriousness for low-income people internationally. This research confirms some previous findings indicating that transport expenses are regressive, consuming a larger proportion of the incomes of the poor than of the rich. The research goes further by showing that both expenditure levels and affordability perceptions vary significantly and systematically across geographic settlement types, and depend to a large extent on the modal and travel characteristics of commuter trips.

Variations in commute expenses, both in absolute terms and relative to commuters' incomes, are firstly and most significantly determined by the mode used to travel. Commuters can be grouped into three broad tiers with similar average expenditure/income ratios. Car users typically incur significantly higher costs than non-car users, if the cost of owning the car is included. Medium-income drivers - a sizable $15 \%$ of commuters nationally - spend up to $80 \%$ of their incomes on travelling to work, although some drivers might offset this expenditure through taking paying passengers or operating cheaper vehicles. A small portion of drivers have extremely long commutes and bear even higher cost burdens. The fact that this group earns only marginally higher average incomes indicates that their long commutes do not necessarily provide access to better-paying jobs, but are simply constrained responses to an inflexible jobs-housing market. The results draw attention to the specific vulnerabilities of middle-income households - a group that has frequently been overlooked in research locally.

The second tier of commuters spends on average about 15 to $20 \%$ of their income on travel to work, and these include high-income car users and public transport users with low or medium incomes. The lowest tier is made up of high-income public transport users, car passengers and walkers, who spend on average less than $4 \%$ of their income on transport to work. From among these, commuters walking long distances tend to complain more about the affordability of transport, providing evidence that motorised mobility is too expensive for some, forcing them to walk longer distances than they would otherwise have done.

If we focus only on public transport modes, the average cost of a public transport trip varies significantly across urban and rural areas in South Africa, sometimes by as much as a factor 
of 10. Geographic patterns of population and land use distribution, public transport supply and infrastructure (especially road) quality seem to influence public transport costs systematically. Worst off appear to be the commuters living in displaced urban settlements or in isolated deep rural locations. Both groups face long commute distances, poor road conditions and few travel alternatives, which combine to raise the cost of motorised travel and perceptions of the severity of transport affordability problems.

Another problem area is in commercial farming districts and around small towns where, although public transport is less costly in general, some workers are forced by affordability constraints to walk excessively long distances. This suggests that current government programmes to improve rural mobility through bicycle distribution and non-motorised transport (NMT) infrastructure provision could indeed help address access problems.

What is the policy significance of the strong effect of location on transport expenditure and affordability? It suggests that well-planned spatially targeted initiatives could be effective in improving affordability and mobility for a range of user types. Road and footpath upgrading in rural areas, both along public transport routes and to improve NMT access to and from main routes, might be the single most effective investment government could make. Policies that reduce the cost of car travel in general (such as reduced fuel levies) might be contestable on the grounds of economic and environmental sustainability. However, land use and housing policies that improve the co-location of affordable housing stock and unskilled and semiskilled job opportunities along public transport corridors, as well as policies that enhance the flexibility of the housing market, would improve the choices available to current car users to reduce their commute cost burdens and lead to significant savings in household expenditure and environmental costs. Such land use-transport policies, perhaps tied to the deployment of emerging rapid public transport networks, are needed both in cities and in former homeland areas.

Current efforts by government to re-direct public transport towards becoming more useroriented and integrated - for instance through the deployment of rapid bus and rail networks - could thus be instrumental in achieving affordability gains. But careful, disaggregate analyses and planning is needed, as this is by no means inevitable: if integrated feederlinehaul networks replace presently direct bus and taxi routes, requiring users to make more transfers than they currently do, overall travel costs might increase and affordability decline significantly even as system efficiency improves. There is also no guarantee that any efficiency gains will be passed on to consumers, given the profit-seeking pricing strategies evident in the public transport market. Achieving equitable and socially progressive fare systems might require government surveillance and perhaps control.

On the question of whether disabled and elderly people face particularly severe affordabilityrelated problems, the data did not clearly indicate this to be the case. While individuals' experiences with access and mobility obviously vary greatly, the disabled as a group do not seem to incur significantly higher public transport expenses than travellers at large, nor do they perceive affordability as significantly more of a problem. However, as the disabled tend to have lower incomes, they do spend greater proportions of their incomes on transport, 
especially in rural areas. It is the inaccessibility rather than the unaffordability of transport that disabled people tend to regard as a more serious constraint to their mobility. The overall implication is that the limited funds that are available to improve public transport in cities should go towards improving accessibility for all, rather than towards lowering fares for all disabled persons as a group. This is not to say that subsidisation is not needed: the evidence shows that both disabled and non-disabled commuters benefit substantially from having access to subsidised bus and rail services. But the benefit stems from the subsidies being available to all low-income workers.

Elderly persons who want to travel seem to be worst off, since they frequently do not qualify for existing subsidies (which are primarily available to workers). If there is a case to be made for expanding concessionary fares to some groups, it could be made for the elderly, whose limited travel needs would add little to public transport subsidy bills.

Methodologically it is clear that transport affordability needs to be treated with more finesse than it is currently. On their own, neither absolute nor relative transport expenditures, nor subjective perceptions of unaffordability, nor data on travel behaviour and immobility, provide a complete picture of the affordability of transport. Further research is needed to understand the link between affordability and welfare, and how this is influenced by specific conditions related to spatial development and transport supply patterns. The aggregate-level results from this study suggest that people living in deep rural areas and displaced urban settlements and medium- to low-income car users in suburbs and urban townships might be priority groups for further study.

\section{Acknowledgments}

The assistance of the Department of Transport in making the NHTS dataset available for analysis is gratefully acknowledged. The analysis and conclusions do not necessarily reflect the views of the DoT.

\section{References}

Behrens, R \& Venter, C, 2006. Unravelling travel costs: Towards improved data collection and transport expenditure policy indicators. Proceedings: 25th Annual Southern African Transport Conference, Pretoria, South Africa. http://hdl.handle.net/2263/6105 Accessed 27 July 2008.

Bernstein, S, Makarewicz, C \& McCarty, K, 2005. Driven to Spend: Pumping Dollars out of Our Households and Communities. Center for Neighbourhood Technology and Surface Transportation Policy Project, Washington, DC. 
Bryceson, DF, Mbara, TC \& Maunder, D, 2003. Livelihoods, daily mobility and poverty in sub-Saharan Africa. Transport Reviews 23(2), 177-96.

Carruthers, R, Dick, M \& Saurkar, A, 2005. Affordability of Public Transport in Developing Countries. Transport Papers TP-3. World Bank, Washington, DC.

DFID (Department for International Development), 2000. Disability, poverty and development. DFID, London, UK.

Diaz Olvera, L, Plat, D \& Pochet, P, 2008. Household transport expenditure in sub-Saharan African cities: Measurement and analysis. Journal of Transport Geography 16(1), 1-13.

DoT (Department of Transport), 2005. National Household Travel Survey 2003: Technical report. Pretoria, South Africa.

DoT (Department of Transport), 2006. National Land Transport Strategic Framework 20062011. Government Gazette no. 29307. Government Printer, Pretoria.

Gannon, CA \& Liu, Z, 1997. Poverty and Transport. Discussion paper, TWU Papers TWU30. World Bank, Washington, DC.

Gomide, A, Leite, S \& Rebelo, J, 2005. Public transport and urban poverty: A synthetic index of adequate service. World Bank, Washington, DC.

Hendriks, SL \& Lyne, MC, 2003. Expenditure patterns and elasticities of rural households sampled in two communal areas of Kwazulu-Natal. Development Southern Africa 20(1), 105-27.

Kane, L, 2006. Transport problems associated with poverty in South Africa. Paper presented at National Household Travel Survey Seminar, CSIR Convention Centre, Pretoria, South Africa.

Lipman, BJ, 2006. A Heavy Load: The Combined Housing and Transportation Burdens of Working Families. Center for Housing Policy, Washington, DC.

Litman, T, 2007. Evaluating Transportation Affordability. Victoria Transport Policy Institute, Victoria, Canada.

Mahapa, SM \& Mashiri, M, 2001. Social exclusion and rural transport: Gender aspects of a road improvement project in Tshitwe, Northern Province. Development Southern Africa 18(3), 365-76.

Mashiri, M, Nkuna, Z, Chakwizira, J \& Maponya, G, 2008. Strengthening informal healthcare delivery: Gender perspectives. Proceedings: 27th Annual Southern African Transport Conference, Pretoria, South Africa. http://hdl.handle.net/2263/6254 Accessed 25 November 2008. 
Mhlongo, M, Green, CA, Morojele, N, Badenhorst, W, Naude, A \& Mashiri, M, 1999. Developing a typology of rural areas of South Africa for use in a rural transport strategy. Contract report CR-99/076, Department of Transport, Pretoria, South Africa.

Nyarirangwe, M \& Mbara, T, 2007. Public transport service modal choice, affordability and perceptions in an unpalatable economic environment: The case of an urban corridor in Harare (Zimbabwe). Proceedings: 26th Annual Southern African Transport Conference, Pretoria, South Africa. http://hdl.handle.net/2263/6007 Accessed 28 July 2008.

OSDP (Office on the Status of Disabled Persons), 1999. White Paper on an Integrated National Disability Strategy. Government Printer, Pretoria.

Sanchez, TW, Makarewicz, C, Haas, PM \& Dawkins, CJ, 2007. Transportation Costs, Inequities, and Tradeoffs. Paper presented at 86th Annual Meeting of the Transportation Research Board, Washington, DC.

Statistics South Africa, 2008. Income and Expenditure of Households 2005/2006. Statistical release P0100. Pretoria, South Africa.

STPP (Surface Transportation Policy Project), 2003. Transportation Costs and the American Dream: Why a Lack of Transportation Choices Strains the Family Budget and Hinders Home Ownership. Special Report: STPP, Washington, DC.

TRL Ltd (Transport Research Laboratory), 2003. Activity Patterns, Transport and Policies for the Urban Poor: Urban Mobility Planning Guidelines. Final Report. Project Report PR/INT/259/02. Department for International Development, London, UK.

Turner, J \& Fouracre, P, 1995. Women and transport in developing countries. Transport Reviews 15(1), 77-96.

Venter, CJ \& Behrens, R, 2005. Transport expenditure: Is the $10 \%$ policy benchmark appropriate? Proceedings: 24th Annual Southern African Transport Conference, Pretoria, South Africa. http://hdl.handle.net/2263/7030 Accessed 5 November 2008.

Venter, CJ, Savill, T, Rickert, T, Bogopane, H, Venkatesh, A, Camba, J, Mulikita, N, Stone, J \& Maunder, D, 2002. Enhanced Accessibility for People with Disabilities Living in Urban Areas. Unpublished Project Report PR/INT/248/02. TRL Ltd., Crowthorne, UK. www.globalride-sf.org/images/DFID.pdf Accessed 5 May 2008.

World Bank, 2002. Cities on the Move: A World Bank Urban Transport Strategy Review. World Bank, Washington, DC. 
Table 1: Reasons given for immobility (by person type, income and settlement type) ('other' not shown, so columns do not add up to $100 \%$ )

\begin{tabular}{llcccccc}
\hline $\begin{array}{l}\text { Person } \\
\text { type }\end{array}$ & $\begin{array}{l}\text { Reason given for } \\
\text { immobility }\end{array}$ & $\begin{array}{c}\text { Urban } \\
\text {-poor }\end{array}$ & $\begin{array}{c}\text { Urban- } \\
\text { medium }\end{array}$ & $\begin{array}{c}\text { Urban- } \\
\text { rich }\end{array}$ & $\begin{array}{c}\text { Rural- } \\
\text { poor }\end{array}$ & $\begin{array}{c}\text { Rural- } \\
\text { medium }\end{array}$ & $\begin{array}{c}\text { Rural- } \\
\text { rich }\end{array}$ \\
\hline $\begin{array}{l}\text { Disabled } \\
\text { (n=2258) }\end{array}$ & Personal (\%) & 88 & 89 & 91 & 88 & 88 & 91 \\
& Affordability (\%) & 2 & 2 & 0 & 6 & 3 & 1 \\
& Access (\%) & 8 & 7 & 8 & 6 & 9 & 7 \\
\hline Elderly & Personal (\%) & 94 & 95 & 96 & 90 & 95 & 97 \\
$(\mathrm{n}=4244)$ & Affordability (\%) & 4 & 2 & 1 & 8 & 4 & 2 \\
& Access (\%) & 1 & 1 & 1 & 1 & 1 & 1 \\
\hline All & Personal (\%) & 88 & 93 & 95 & 88 & 91 & 93 \\
$(\mathrm{n}=41072)$ & Affordability (\%) & 9 & 5 & 2 & 10 & 7 & 4 \\
& Access (\%) & 1 & 1 & 0 & 1 & 1 & 1 \\
\hline
\end{tabular}

Source: National Household Travel Survey 2003 (DoT, 2005)

Table 2: Perceived transport problems (by person type, income and settlement type) ('other' not shown)

\begin{tabular}{|c|c|c|c|c|c|c|c|}
\hline \multirow[b]{2}{*}{$\begin{array}{l}\text { Person } \\
\text { type }\end{array}$} & \multirow{2}{*}{$\begin{array}{l}\text { Transport } \\
\text { problem }\end{array}$} & \multicolumn{6}{|c|}{$\%$ of respondents mentioning problem } \\
\hline & & $\begin{array}{l}\text { Urban } \\
\text {-poor }\end{array}$ & $\begin{array}{c}\text { Urban- } \\
\text { medium }\end{array}$ & $\begin{array}{c}\text { Urban- } \\
\text { rich }\end{array}$ & $\begin{array}{c}\text { Rural- } \\
\text { poor }\end{array}$ & $\begin{array}{c}\text { Rural- } \\
\text { medium }\end{array}$ & $\begin{array}{c}\text { Rural- } \\
\text { rich }\end{array}$ \\
\hline \multirow{4}{*}{$\begin{array}{l}\text { Disabled } \\
(n=1446)\end{array}$} & Access problems & 43 & 44 & 46 & 57 & 65 & 58 \\
\hline & Affordability & 21 & 15 & 6 & 40 & 36 & 37 \\
\hline & Service quality & 32 & 40 & 39 & 33 & 37 & 44 \\
\hline & None & 38 & 36 & 40 & 22 & 16 & 19 \\
\hline \multirow{4}{*}{$\begin{array}{l}\text { Elderly } \\
(n=4522)\end{array}$} & Access problems & 39 & 35 & 30 & 62 & 69 & 66 \\
\hline & Affordability & 21 & 14 & 7 & 48 & 37 & 34 \\
\hline & Service quality & 33 & 31 & 27 & 29 & 35 & 40 \\
\hline & None & 39 & 46 & 53 & 18 & 16 & 17 \\
\hline \multirow{4}{*}{$\begin{array}{l}\text { All } \\
(n=42765)\end{array}$} & Access problems & 44 & 44 & 34 & 66 & 72 & 63 \\
\hline & Affordability & 23 & 18 & 10 & 36 & 34 & 30 \\
\hline & Service quality & 41 & 48 & 38 & 36 & 35 & 40 \\
\hline & None & 33 & 31 & 44 & 17 & 16 & 21 \\
\hline
\end{tabular}

Source: National Household Travel Survey 2003 (DoT, 2005) 
Table 3: Cost and travel behaviour data for work trips of disabled and all workers

\begin{tabular}{|c|c|c|c|c|}
\hline Data & $\begin{array}{c}\text { Urban } \\
\text { disabled }\end{array}$ & $\begin{array}{c}\text { Urban } \\
\text { all }\end{array}$ & $\begin{array}{c}\text { Rural } \\
\text { disabled }\end{array}$ & $\begin{array}{c}\text { Rural } \\
\text { all }\end{array}$ \\
\hline Sample size & 53 & 8037 & 18 & 1648 \\
\hline $\begin{array}{l}\text { Average monthly travel cost to } \\
\text { work, by PT (rand) }\end{array}$ & 164 & 202 & 226 & 201 \\
\hline $\begin{array}{l}\text { PT travel cost / } \\
\text { Personal income (\%) }\end{array}$ & $17.9 \%$ & $14.9 \%$ & $21.8 \%$ & $19.5 \%$ \\
\hline $\begin{array}{l}\text { Average PT cost per trip } \\
\text { (rand) }\end{array}$ & $3.88 *$ & 4.94 & 5.86 & 4.89 \\
\hline
\end{tabular}

Source: National Household Travel Survey 2003 (DoT, 2005)

Note: $\mathrm{PT}=$ public transport

* = significant difference between disabled and all workers, $10 \%$ significance 
Table 4: Cost and travel behaviour data for work trips by public transport, according to location type

\begin{tabular}{|c|c|c|c|c|c|c|c|}
\hline \multirow[t]{2}{*}{ Location type } & \multirow{2}{*}{$\begin{array}{c}\text { Number }(\%) \text { of } \\
\text { observations }\end{array}$} & \multirow{2}{*}{$\begin{array}{c}\text { Average zonal } \\
\text { PT cost (R/trip) }\end{array}$} & \multirow{2}{*}{$\begin{array}{c}\text { Average } \% \text { of income } \\
\text { spent on transport }\end{array}$} & \multirow{2}{*}{$\begin{array}{c}\% \text { with affordability } \\
\text { problem* }\end{array}$} & \multicolumn{3}{|c|}{ \% trips to work by mode** } \\
\hline & & & & & walking & taxi & bus/rail \\
\hline Rural arid farming & $1666 \quad(6 \%)$ & 2.96 & 13 & $13 \%$ & $60 \%$ & $12 \%$ & $2 \%$ \\
\hline Rural commercial & $(29 \%)$ & 3.68 & 19 & $18 \%$ & $49 \%$ & $16 \%$ & $7 \%$ \\
\hline Rural homeland & $(7 \%)$ & 5.37 & 14 & $31 \%$ & $43 \%$ & $25 \%$ & $9 \%$ \\
\hline Metro core & $(2 \%)$ & 4.27 & 18 & $12 \%$ & $23 \%$ & $31 \%$ & $20 \%$ \\
\hline Urban periphery & $(44 \%)$ & 4.69 & 27 & $16 \%$ & $14 \%$ & $27 \%$ & $15 \%$ \\
\hline Urban hinterland & $(12 \%)$ & 5.62 & 21 & $19 \%$ & $21 \%$ & $28 \%$ & $20 \%$ \\
\hline
\end{tabular}

Source: National Household Travel Survey 2003 (DoT, 2005)

Note: $\mathrm{PT}=$ public transport

* Respondents identifying affordability as one of two most important transport problems

** Car and other modes not shown

Table 5: Clusters of commuters facing distinctly different work trip expenditure/affordability realities

\begin{tabular}{|c|c|c|c|c|c|c|}
\hline $\begin{array}{c}\text { Transport user } \\
\text { group* }\end{array}$ & $\begin{array}{c}\text { Number (\%) of } \\
\text { observations }\end{array}$ & $\begin{array}{c}\text { Average trip cost } \\
\text { to work } \\
\text { (R/one-way trip) }\end{array}$ & $\begin{array}{l}\text { Average income } \\
\text { (R/person/month) }\end{array}$ & $\begin{array}{l}\text { Average \% of income } \\
\text { spent on transport }\end{array}$ & $\begin{array}{c}\text { \% with } \\
\text { affordability } \\
\text { problem* }\end{array}$ & Mode use \\
\hline Short walkers & $(17 \%)$ & 0.00 & 1545 & $0 \%$ & $18 \%$ & $100 \%$ walk \\
\hline Long walkers & $3783 \quad(13 \%)$ & 0.00 & 1198 & $0 \%$ & $22 \%$ & $100 \%$ walk \\
\hline High-inc PT users & $(1 \%)$ & 5.62 & 7878 & $3 \%$ & $19 \%$ & $67 \%$ taxi, $33 \%$ rail/bus \\
\hline Med-inc PT users & $(17 \%)$ & 4.88 & 2657 & $9 \%$ & $20 \%$ & $64 \%$ taxi, $36 \%$ rail/bus \\
\hline Low-inc PT users & $(17 \%)$ & 3.81 & 841 & $21 \%$ & $24 \%$ & $67 \%$ taxi, $33 \%$ rail/bus \\
\hline Extreme car users & $(2 \%)$ & 52.89 & 4386 & $125 \%$ & $13 \%$ & $100 \%$ car \\
\hline High-inc car (drivers \& pass) & $(11 \%)$ & 35.66 & 11177 & $20 \%$ & $7 \%$ & $100 \%$ car \\
\hline Med-inc car drivers & $(15 \%)$ & 34.77 & 3158 & $79 \%$ & $12 \%$ & $100 \%$ car \\
\hline Med-inc car passengers & $(7 \%)$ & 1.13 & 1980 & $3 \%$ & $16 \%$ & $100 \%$ car \\
\hline Total & $28066 \quad(100 \%)$ & 11.85 & 3051 & $22 \%$ & $18 \%$ & \\
\hline
\end{tabular}

Source: National Household Travel Survey 2003 (DoT, 2005)

* Respondents identifying affordability as one of two most important transport problems 
Table 6: Results of binomial probit model of factors explaining perception of unaffordable transport (significant variables in bold)

\begin{tabular}{|c|c|c|c|c|}
\hline Type & Variable & Description & Coefficient & t-statistic \\
\hline $\begin{array}{l}\text { Trip } \\
\text { variables }\end{array}$ & $\begin{array}{l}\text { Actual trip cost } \\
\text { Percent spent on } \\
\text { transport } \\
\text { Trip length dummy } \\
\text { Taxi used }\end{array}$ & $\begin{array}{l}\text { R/one-way trip } \\
\text { Monthly trip } \\
\text { cost/income } \\
1 \text { if origin and } \\
\text { destination in different } \\
\text { zones } \\
1 \text { if trip made by taxi }\end{array}$ & $\begin{array}{l}0.00121 \\
\mathbf{0 . 0 0 0 2 4} \\
-\mathbf{0 . 0 8 5 4 6}\end{array}$ & $\begin{array}{l}1.21 \\
2.22 * * \\
-4.07 * *\end{array}$ \\
\hline Personal & Disabled & 1 if person is disabled & -0.06423 & -0.57 \\
\hline $\begin{array}{l}\text { Commuter } \\
\text { type (mode } \\
\text { \& income) }\end{array}$ & $\begin{array}{l}\text { Extreme car commute } \\
\text { High-income car user } \\
\text { Medium/low-income car } \\
\text { driver } \\
\text { Medium/low-income car } \\
\text { passenger } \\
\text { High-income PT user } \\
\text { Medium/low-income } \\
\text { PT user } \\
\text { Long walker } \\
\text { Short walker }\end{array}$ & $\begin{array}{l}\text { Reference case } \\
1 / 0 \\
1 / 0 \\
1 / 0 \\
1 / 0 \\
1 / 0 \\
1 / 0 \\
1 / 0\end{array}$ & $\begin{array}{l}- \\
-\mathbf{0 . 3 4 9 2 5} \\
-0.08406 \\
\\
0.03176 \\
\\
0.17162 \\
\mathbf{0 . 3 0 3 1 5} \\
\\
\mathbf{0 . 2 3 9 3 0} \\
0.11636\end{array}$ & $\begin{array}{l}-- \\
-4.48 * * \\
-1.13 \\
0.35 \\
1.55 \\
3.54 * * \\
\\
2.76^{* *} \\
1.35\end{array}$ \\
\hline $\begin{array}{l}\text { Location } \\
\text { type }\end{array}$ & $\begin{array}{l}\text { Rural arid farming } \\
\text { Rural commercial } \\
\text { Rural homeland } \\
\text { Metro core } \\
\text { Urban periphery } \\
\text { Urban hinterland }\end{array}$ & $\begin{array}{l}1 / 0 \\
1 / 0 \\
1 / 0 \\
\text { Reference case } \\
1 / 0 \\
1 / 0\end{array}$ & $\begin{array}{l}0.07553 \\
0.27353 \\
\mathbf{0 . 6 5 4 1 5} \\
- \\
\mathbf{0 . 2 2 2 7 9} \\
\mathbf{0 . 2 9 5 3 9}\end{array}$ & $\begin{array}{l}0.93 \\
3.76 * * \\
8.49 * * \\
-- \\
3.11 * * \\
3.96 * *\end{array}$ \\
\hline Constant & Constant & 1 & -1.28651 & $-12.01 * *$ \\
\hline & $\begin{array}{l}\text { N=28066 } \\
\text { Log-likelihood function } \\
\text { Restricted log- } \\
\text { likelihood } \\
\text { Chi-squared }\end{array}$ & \multicolumn{3}{|l|}{$\begin{array}{l}-12639.27 \\
-13043.51 \\
808.489\end{array}$} \\
\hline
\end{tabular}

** Coefficient significant at 95\% confidence level 


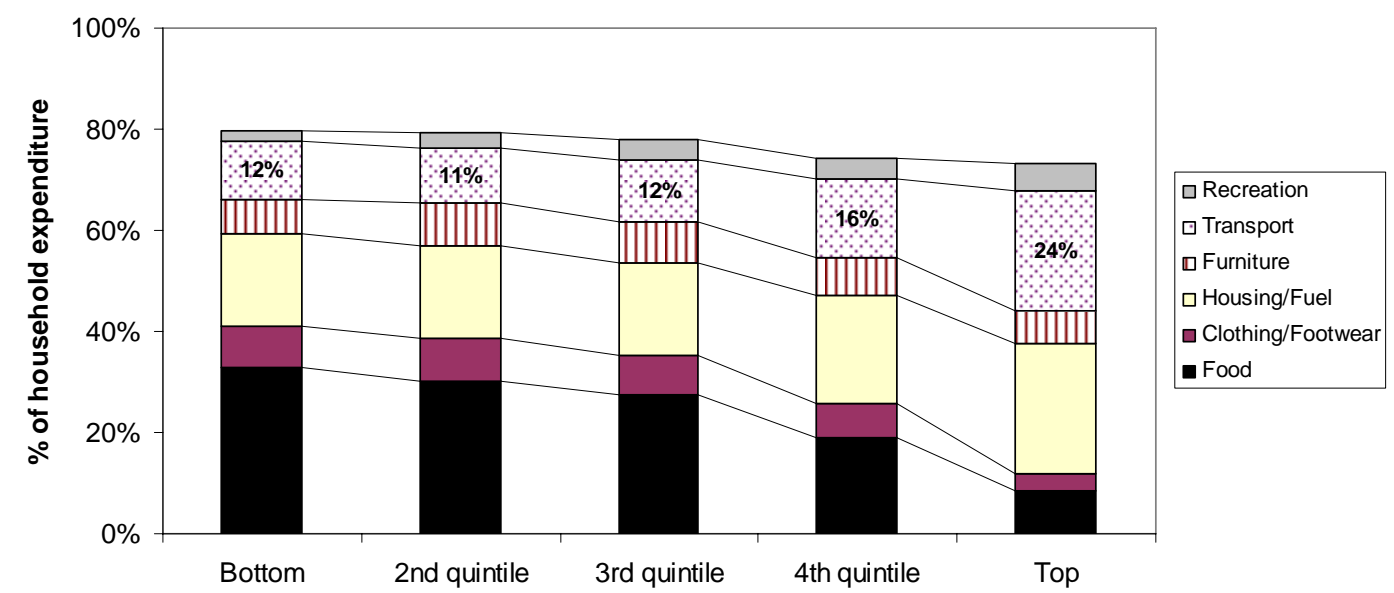

Figure 1: Share of household expenditure spent on major categories of goods, by household income quintile. Based on data from Income and Expenditure Survey 2005/6, South Africa $(n=24000)$

Source: StatsSA (2008)

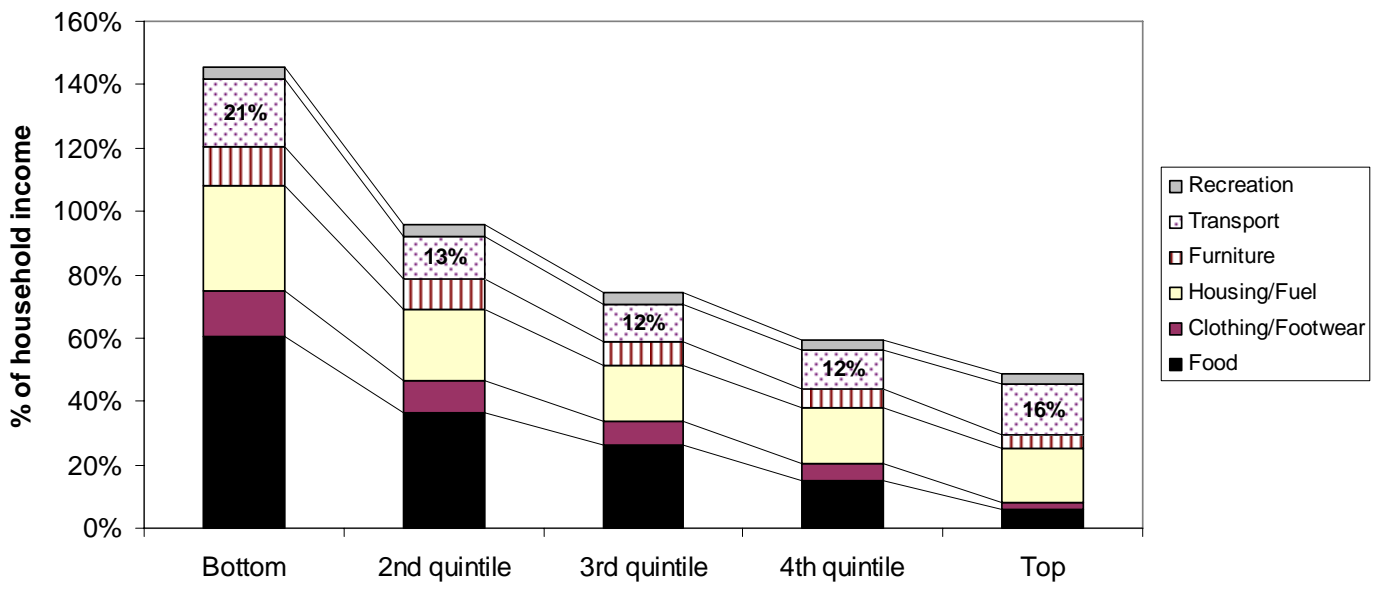

Figure 2: Share of household income spent on major categories of goods, by household income quintile. Based on data from Income and Expenditure Survey 2005/6, South Africa (n=24 000) Source: StatsSA (2008) 


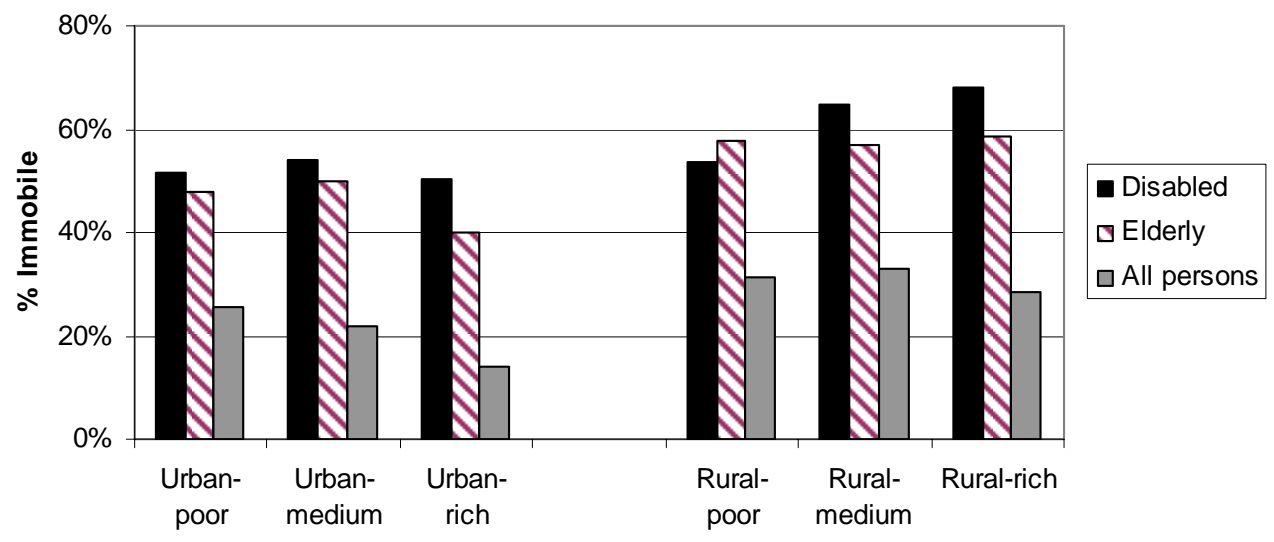

Figure 3: Incidence of immobility (persons who did not travel at all) by person type, income and settlement type $(n=3947$ disabled, $n=8112$ elderly, $n=163064$ all $)$

Source: National Household Travel Survey 2003 (DoT, 2005)

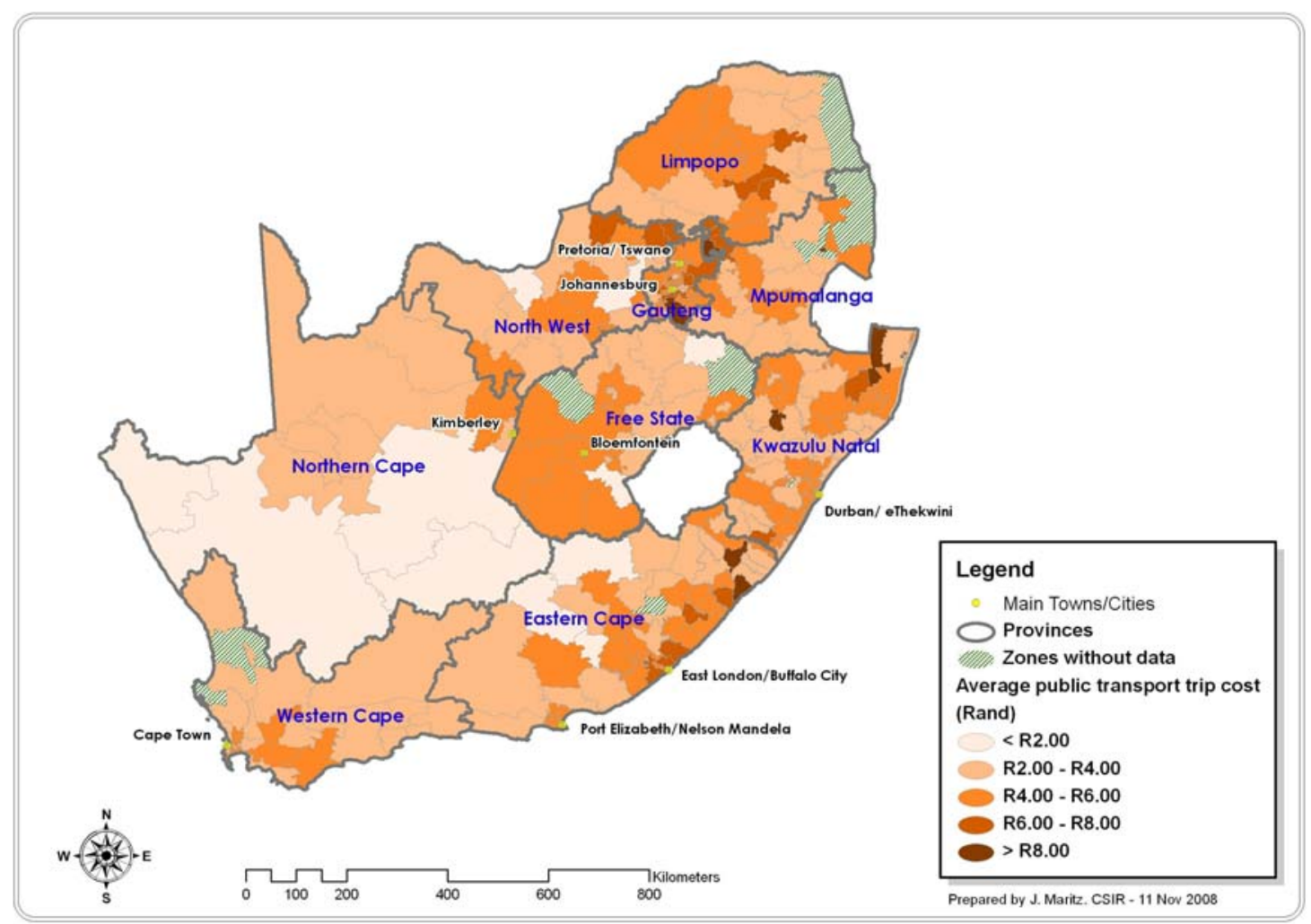

Figure 4: Average cost of a public transport trip to work, per NHTS zone

Source: Calculated from National Household Travel Survey 2003 (n=9582), (DoT, 2005) 